\title{
Student Engagement in University STEM Course Through Digital Video Project Using SAMR Model
}

\author{
Iskandar Dzulkarnain ${ }^{1, *}$, Nabilla Afzan Abdul Aziz ${ }^{1}$, Suswandari $^{2}$, and Ihsana El \\ Khuluqo $^{2}$
}

${ }^{1}$ Petroleum Engineering Department, Universiti Teknologi PETRONAS, Malaysia. ${ }^{2}$ Universitas Muhammadiyah Prof Dr HAMKA, Indonesia.

*Corresponding author: iskandar_dzulkarnain@utp.edu.my

\begin{abstract}
Fostering student engagement in a university STEM course is a challenge since typical student nowadays is a digital native. Thus, adoption of technology, particularly one that the students interact in their online milieu is a prerequisite for a successful learning experience. In this context instructor needs to integrate elements such as content creation and social interaction when delivering the course. This becomes imperative in recent times when online teaching and learning becomes the norm. In this study, we present findings from an engineering course which incorporate the elements of content creation and social interaction through video projects collaboratively created by our students. The main highlight of this course is the digital video project which was designed according to the SAMR (Substitution, Augmentation, Modification and Redefinition) model. The objective of this study is to find relationship between the project and students' achievement of course outcome as proxy for students' engagement. The methodology used a quasi-experimental method where the achievement of one target learning outcome of this course as measured with in-house OBE software with the cohort doing the video project is compared with cohort from past semester as control group. The results suggest significant relationship between video project activity and achievement of learning outcome. It is also found that the video project correlates with improved student engagement in the course. The findings from this study provide a framework for instructor in a university-level STEM course to design and integrate technology in their course delivery.
\end{abstract}

Keywords: student engagement, SAMR model, digital video project.

\section{INTRODUCTION}

Student engagement in the context of higher education where online learning has become ubiquitous presented unique set of challenges for instructors. Part of the challenge is designing coursework content that cater to higher-level cognitive skills while sustaining their interest. This is imperative for instructors teaching STEM courses in university. Since the students nowadays are well-versed in technology, instructors must upgrade their teaching strategies to incorporate technology tools students are familiar with in the learning environment. This will potentially help to unleash the students' innate talent and creativity to become active learner by engaging in the course materials through collaborative knowledge creation. Instructors who aim to transform their teaching strategies and their students' learning experience by adopting technology needs a framework as a guideline to structure the course delivery. In the literature SAMR model provides the necessary framework for instructors to select, evaluate and eventually adopt the suitable technology. In this context it is interesting to investigate how a coursework project, created through the SAMR 
model helps students to achieve better learning outcome as well as maintain their level of engagement with the coursework.

\section{LITERATURE REVIEW}

Over the past two decades, the concept of student engagement has become widely popular [1], despite the lack of agreement on its definition [2], [3]. The present study draws on Fredricks et al.'s [4] definition, which understands engagement as a student's commitment or investment in relation to his or her learning activities. It is conceived as a meta-concept that includes behaviors, cognitions, emotions [4], and social interactions [5]. According to Fredricks et al. [1] and Wang et al. [5], engagement consists of four distinct but interrelated components: (1) behavioral: involvement in academic and class-based activities, attention, participation, concentration, homework completion, and adherence to classroom rules; (2) emotional: positive emotions toward teachers, classmates, and classroom activities; interest, enjoyment, and identification with school or subject domains; (3) cognitive: investment in learning, self-regulation, persistence, effort in comprehension of complex ideas or mastery of difficult skills; and (4) social: quality of social interactions, participation with classmates, and pro-social behavior in classrooms.

Rasheed et al. [6] and Koranteng et al. [7] view student engagement as "the amount of physical and psychological energy that the students devote to the academic work", while creativity is understood as the 'production of new and useful ideas' [8]. Students' engagement and creativity are expected to be facilitated with knowledge sharing among students. Josefsson et al. [9], argue that student engagement is a key factor for student's achievement and learning. Fredricks et al. [4], suggested that different factors affect student engagement. They discovered three core dimensions of student engagement that includes behavioral engagement, emotional engagement, and cognitive engagement. These three components influence students from different perspectives and keep them engaged in different academic efforts.

In higher education setting, fostering student engagement in cognitive, behavioral, and emotional dimension is a key activity which contributes to effective learning [10]. According to Krause and Coates [11], effective learning will be the desired outcome when engaged students invest their time, energy, and resources in learning activities. A study by Umbach and Wawrzynki [12] directs the attention on the importance of instructors' interaction and teaching approach to engage university students in their learning. More specifically, their study found that instructors who apply active and collaborative teaching strategies correspond with higher levels of engagement and learning from their students. Interaction between instructors and students that promote higher-order cognitive activities from these teaching strategies culminate in students being challenged academically which add value to their learning experiences. Another study by Zepke and Leach [13] from their synthesis of recent literature further support the central role of instructors in student engagement. They propose that student engagement is better achieved when instructors create learning experience that is both active and collaborative. Student engagement can be further enhanced when the learning experiences are challenging, enriching and extend the students' academic abilities. From these studies, it is imperative that instructors play an active role in designing their coursework to incorporate findings from these studies to support student engagement.

Digital video creation has been recognized as element that instructors can incorporate in their coursework to encourage active and collaborative learning which leads to student engagement [14]. In their paper Hung et al. suggest that digital video creation project engage the students by turning them into playing active role in the learning process. Through the process of creating the videos, the students internalize meaningful learning constructs such as active, constructive, collaborative, intentional and authentic. Furthermore, the videos created from the project encapsulates comprehensive approach by integrating audio-visual effects which will be public artefact once the completed videos are shared in online platform. The same conclusion is shared by Hafner and Miller [15] when discussing the outcome of their digital video project for a STEM class. They posited the project, in addition to creating a technologically rich learning environment, also helps to build a strong learner autonomy. This means autonomous learner who engaged in the video project develops ability to reflect, interact, experiment, and improve on their learning. Nikitina [16] work also support this view of fostering learner autonomy through video project. Her work demonstrates that learner autonomy is developed when students actively participate and cooperate to contribute towards completing the project according to their various capacities.

Although the benefits of incorporating digital video project have been well documented as evident from the above studies, instructors still need proper guidance to effectively implement video projects in classroom [17]. Within this context, a framework called SAMR (Substitution, Augmentation, Modification and Redefinition) model was developed by Dr Ruben Puentedura [18]. The model has been used to evaluate instructor's integration of digital technology in the classroom [19], [20]. According to Hamilton et al. [18], Puentedura's SAMR model consisted of four levels that instructors can use to select and adopt technology when 
designing coursework. The first two levels, Substitution and Augmentation, corresponds to activities where technology directly substitute existing learning activity without significant functional change (Substitution) or slightly improved functionality (Augmentation). Activities that lie within these levels are said to contribute to learning enhancement. Greater benefits in terms of learning transformation can be achieved when instructors design their coursework to target the Modification and Redefinition levels [20]. Modification refers to adoption of technology that allows the task to be redesigned significantly while Redefinition uses technology as enabler for creation of new tasks which are not possible previously. Romrell et al. [20] and Geer et al. [19] provides excellent case studies of instructors designing their coursework based on the SAMR model.

However, Romrell et al. [20] work focuses more on mobile devices while Geer et al. [19] investigates the use of iPads. Both do not specifically target STEM students in their study or creation of digital video project as part of the coursework. In this study, we investigate the digital video project creation within the framework of SAMR among students taking STEM subject in university. The aim is to evaluate whether the digital video project promotes achievement of course learning outcome and student engagement.

\section{METHODOLOGY}

This study was conducted with two groups of students: one cohort from the January 2019 semester (N = 78) and another cohort from the September 2019 semester $(\mathrm{N}=48)$. Both cohorts enrolled in an undergraduate engineering course at a private university in Malaysia. Most of the students were in their second year of undergraduate education. The research process consisted of creation of group video projects for cohort in September 2019 semester (experimental group) and comparing the effectiveness of the video project assignments in achieving a specific course outcome with the cohort in January 2019 semester (control group). This was done using correlation analysis and independent samples T-test, both calculated using the non-parametric methods. Since no survey instrument was used to measure students' engagement, we assumed the score for specific course outcome achievement, which was obtained from UTP internal OBE (Outcome-Based Education) software as the proxy measurement for students' engagement. In this study we attempt to answer the following two questions: a) Is there relationship between video project and achievement of course outcome? b) Is there significant difference in course outcome achievement between cohort taking the video project and the cohort who did not?. The results obtained from these questions will determine to what extent student engagement is achieved through the video project.

\subsection{Group Video Project Assignment}

The group video project assignment was designed according to the SAMR model. This model was developed by Ruben Puentedura to provide framework for integrating technology into teaching [18], [21]. The purpose of this model is to help instructors adopt technology effectively to improve students' engagement level. In this study, we redesign the assessment of one chapter in a STEM course; previously the assessment was done through end-of-chapter quiz on a printed quiz sheet. At this stage, the students' level of engagement is minimal since it was the instructor who asked most of the questions. Figure 1 provides the workflow, showing how instructors can apply the SAMR model to elevate the level of students' engagement. Clearly the "Redefinition" level is the ultimate target since this stage fosters the highest level of student's engagement. At this stage, students are doing most of the questioning instead of the instructor, which reflects their engagement with the course material. Accordingly, the original penand-paper quiz was redesigned to be a group video project assignment. 


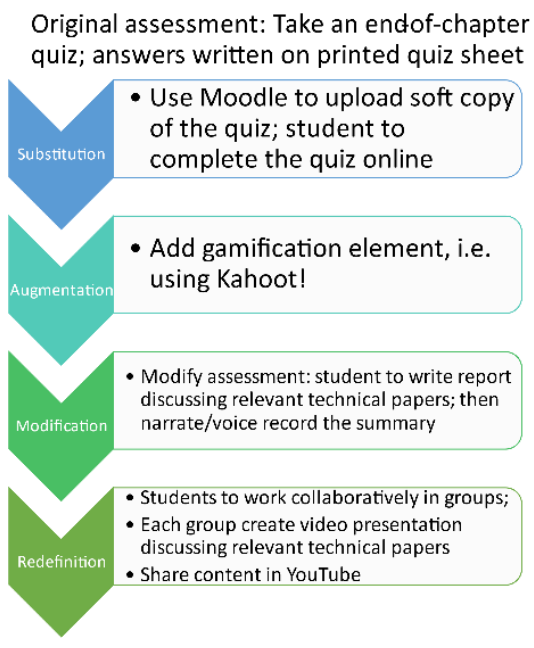

Figure 1. How assessment for one chapter in a STEM course is redesigned according to the SAMR model. The "Redefinition" stage is the stage with the most level of students' engagement.

The application of SAMR model in the delivery of the group video project for September 2019 cohort is shown in Figure 2. The students were asked to form groups of 4-5 students and select a project topic for their video content. The topics were based on selected technical papers (www.onepetro.org) related to the materials covered in class. The students were then given specific instructions and evaluation rubric before working on their projects. For the next five weeks of 12week semester, the students worked collaboratively to create content for a ten-minute video presentation. During this period, the instructor was available during the tutorial hours to provide guidance and feedback on their progress. At the end of the project, they uploaded the completed videos in YouTube (www.youtube.com). The instructor then evaluated the videos based on the rubric.

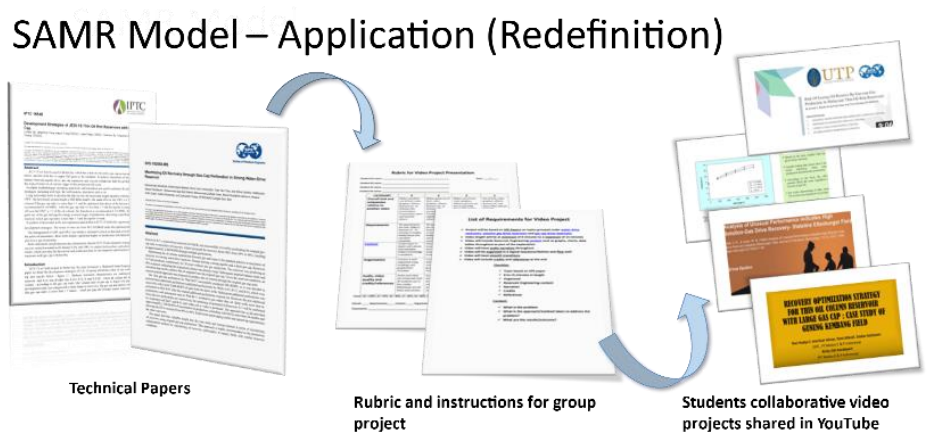

Figure 2. Application of SAMR model in "Redefinition" stage to deliver group video project in a STEM course.

\subsection{Data Collection and Analysis}

The marks obtained by each group formed part of the coursework marks which were input into UTP OBE (Outcome-Based Education) software. The application of this internal software (see Figure 3) has been described previously by Ovinis et al. [22] to evaluate students' achievement of program outcomes (POs) as mapped against course outcomes (COs). In this study, we focused on a specific course outcome - course outcome 3 (see Figure 4) to investigate whether the video project assignment is effective in improving achievement of this course outcome. As such, the variables that were used in this study are PROJ, the group video project marks from the September 2019 cohort and $\mathrm{CO} 3$, the course outcome scores from both January and September 2019 cohorts. All the marks were obtained from the OBE software. For statistical analysis, we used the open-source jamovi [23] software. 


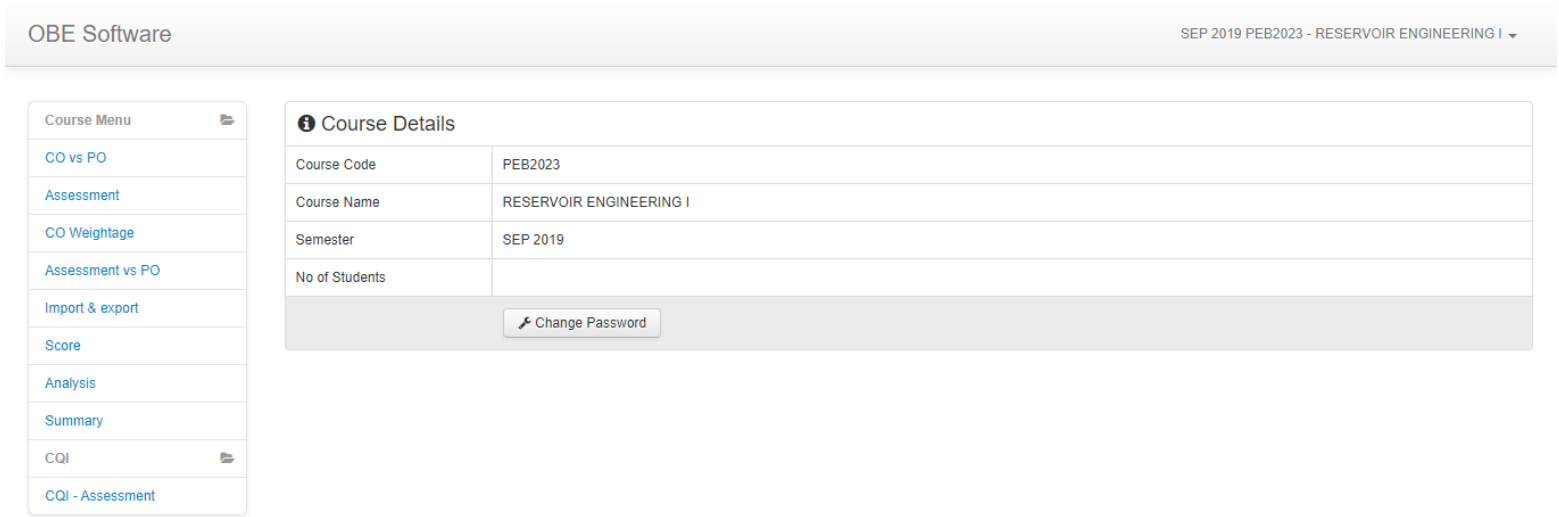

Figure 3. Screenshot of UTP's Outcome-Based Education (OBE) software.

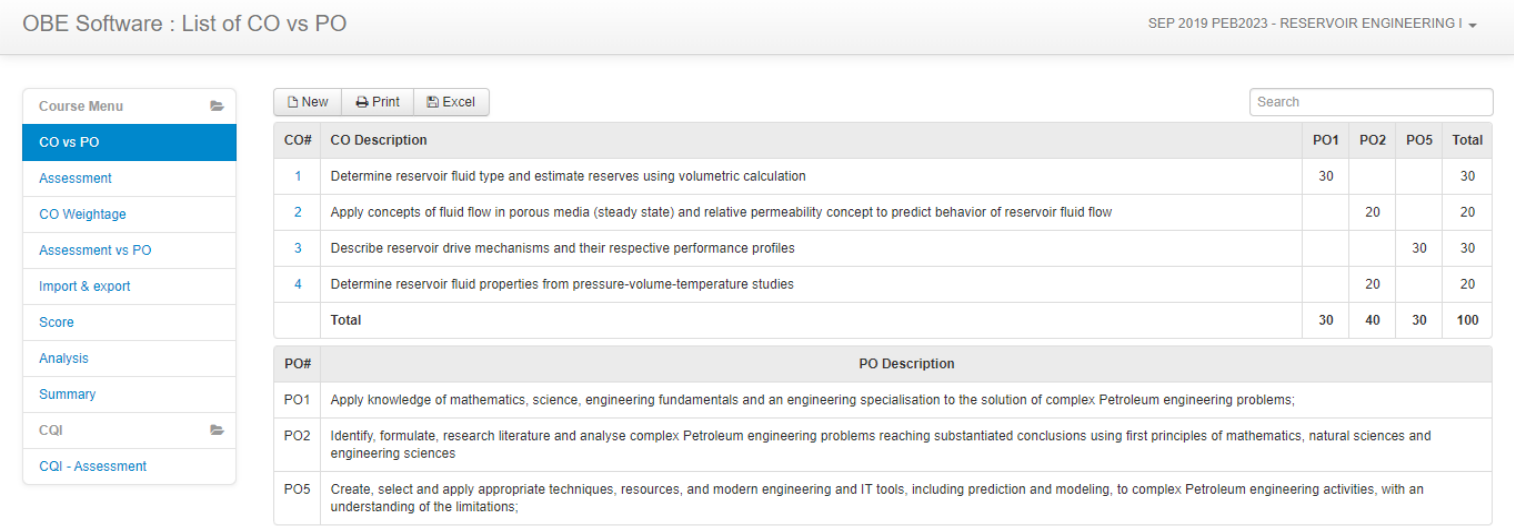

Figure 4. Course outcome (CO) and program outcome (PO) for the course evaluated in this study. We focused on $\mathrm{CO} 3$ and investigate effectiveness of video project assignment to improve achievement of this course outcome.

\section{RESULTS AND DISCUSSION}

To test effectiveness of the video project in improving achievement of course outcome, we conducted non-parametric statistical analysis on the group video project marks and the course outcome score. Non-parametric analysis was performed due to the small sample size and the non-normal distribution of the samples [24]. Furthermore, the intervention (group video project assignment) was done on samples without random assignment. This is because the study used quasi-experimental method where participants were selected solely based on the semester they registered for the course. The non-parametric analyses conducted are the Spearman's rho correlation analysis to investigate relationship between the project marks and course outcome score (CO3); and the Mann-Whitney $U$ to investigate significant difference between two independent groups - September 2019 cohort with the intervention and January 2019 cohort without the intervention. The results are discussed here based on the research questions posed earlier.

Question 1: Is there relationship between video project assignment (PROJ) and student's achievement of course outcome (CO3)?

To answer this question, we used the results from September 2019 cohort $(\mathrm{N}=48)$ which performed the video project activity. Based on the descriptive statistics shown as box plots in Figure 5 below, the mean, median and standard deviation for the PROJ variable are 85.6, 85.0 and 8.10 respectively; while for the $\mathrm{CO} 3$ variable the mean, median and standard deviation are 83.8, 85.8 and 10.2. Clearly, based on descriptive statistics alone it is not sufficient to find whether there exists significant relationship between both variables. Therefore, we conducted correlation analysis using Spearman's rho method. 


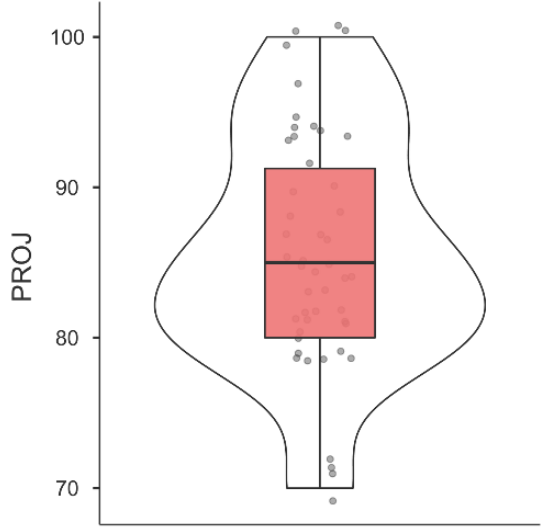

(a)

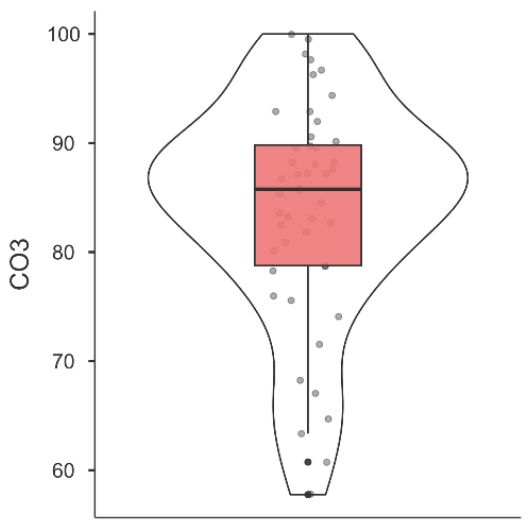

(b)

Figure 5. Box plots showing the mean, standard deviation and distribution of (a) group video project score (PROJ); and (b) course outcome (CO3) score.

The results from Spearman's rho analysis are presented in Figure 6 and Table 1. Figure 6 shows a positive correlation between PROJ and $\mathrm{CO} 3$ variables. This is further confirmed from Spearman's rho analysis in Table 1. Based on these results, $r_{s}(48)=$ $+0.533, p<.001$ which means the positive correlation is significant. This indicates that for the September 2019 cohort, the video project assignment correlates with improved students' achievement of the course outcome. The results confirm there exist significant relationship between video project assignment and students' achievement of course outcome.

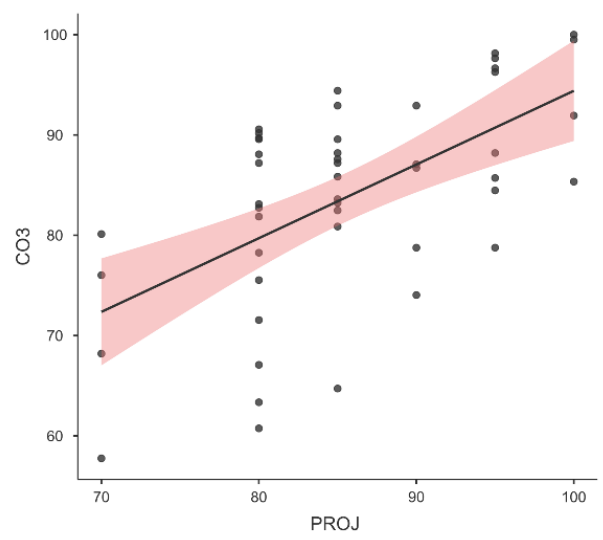

Table 1. Statistics from Spearman's rho analysis

Figure 6. Correlation plot between $\mathrm{CO} 3$ and PROJ variable showing linear relationship

\begin{tabular}{llll}
\multicolumn{4}{c}{ variable showing linear relationship } \\
\hline & & CO3 & PROJ \\
\hline CO3 & Spearman's rho & - & \\
& p-value & - & \\
PROJ & Spearman's rho & 0.533 & - \\
& p-value & $<.001$ & - \\
\hline
\end{tabular}

Question 2: Is there significant difference in course outcome achievement (CO3) between the cohort with the video project intervention (September 2019) and the cohort without intervention (January 2019)? 
For this question, our hypothesis is that students who completed the video project assignment show better achievement in the course outcome (as measured from CO3 score) than the control group. Descriptive statistics presented as box plots in Figure 7 provides visual evidence the intervention improves the course outcome score in September 2019 ( $\mathrm{N}=48)$ compared to January
$2019(\mathrm{~N}=78)$. This is because the mean and median scores for September 2019 are 83.8 and 85.8 respectively; an improvement over January's mean and median scores of 63.5 and 64.9. To confirm whether the differences are significant, we conducted Mann-Whitney $\mathrm{U}$ test as non-parametric version of independent samples T-test. This is shown in Table 2.

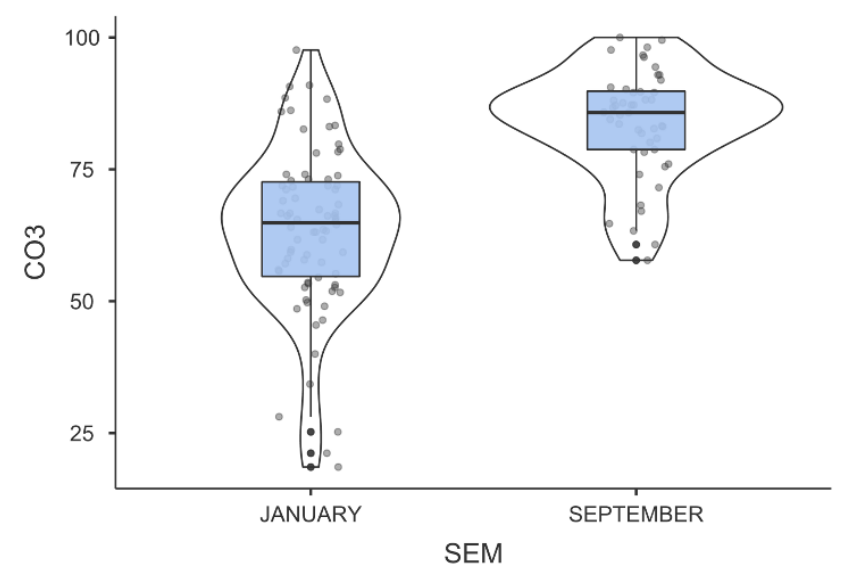

Figure 7. Box plots showing the mean, standard deviation and distribution for course outcome achievement between January 2019 (without intervention) and September 2019 (with intervention) cohort.

Table 2. Statistic results from Mann-Whitney U test

\begin{tabular}{lcccccc}
\hline & & & \multicolumn{2}{c}{$\mathbf{9 5 \%}$ confidence interval } & \\
\cline { 5 - 6 } & & statistic & $\mathbf{p}$ & Lower & Upper & Cohen's d \\
\hline CO3 & Mann-Whitney U & 506 & $<.001$ & -24.7 & -15.7 & -1.47 \\
\hline
\end{tabular}

The results for Mann-Whitney $U$ test $(U=506$, $\mathrm{p}<.001)$ indicates the difference between both cohorts are significant. This means the data support that the video project activity as effective method to improve students' achievement of course outcome. Since CO3 score is also used as proxy for measuring student's engagement with the learning outcome, the data also support video project assignment as effective to promote students' engagement.

\section{CONCLUSION}

Overall, this study provides the workflow according to the SAMR model to implement technology in designing students' project in a STEM course. As part of this study, we evaluate effectiveness of the technologybased video project to improve achievement of target course outcome (CO3). The results were analyzed using correlation analysis which revealed strong relationship between completion of the video project and achievement of $\mathrm{CO} 3$. Further statistical comparison of significance between two cohorts (January 2019 and September 2019) indicated that achievement of CO3 was better for cohort which performed the video project (September 2019) than the cohort in the control group (January 2019). Since the achievement score for CO3 was also used as proxy measurement for students' engagement, both results from correlation analysis and independent groups test also support the video project as effective method to improve students' engagement.

\section{ACKNOWLEDGMENTS}

The authors would like to acknowledge financial support given from UTP-UHAMKA International Collaboration Research Fund Grant No. 015ME0-177 to conduct this study. 


\section{REFERENCES}

[1] J. A. Fredricks, M. Filsecker, and M. A. Lawson, "Student engagement, context, and adjustment: Addressing definitional, measurement, and methodological issues," Learn. Instr., vol. 43, pp. 1-4, Jun. 2016, doi: 10.1016/j.learninstruc.2016.02.002.

[2] R. Azevedo, "Defining and Measuring Engagement and Learning in Science: Conceptual, Theoretical, Methodological, and Analytical Issues," Educ. Psychol., vol. 50, no. 1, pp. 84-94, Jan. 2015, doi: 10.1080/00461520.2015.1004069.

[3] M. Boekaerts, "Engagement as an inherent aspect of the learning process," Learn. Instr., vol. 43, pp. 76-83, Jun. 2016, doi: 10.1016/j.learninstruc.2016.02.001.

[4] J. A. Fredricks, P. C. Blumenfeld, and A. H. Paris, "School Engagement: Potential of the Concept, State of the Evidence:," Rev. Educ. Res., Mar. 2004, doi: 10.3102/00346543074001059.

[5] M.-T. Wang, J. A. Fredricks, F. Ye, T. L. Hofkens, and J. S. Linn, "The Math and Science Engagement Scales: Scale development, validation, and psychometric properties," Learn. Instr., vol. 43, pp. 16-26, Jun. 2016, doi: 10.1016/j.learninstruc.2016.01.008.

[6] M. I. Rasheed, M. J. Malik, A. H. Pitafi, J. Iqbal, M. K. Anser, and M. Abbas, "Usage of social media, student engagement, and creativity: The role of knowledge sharing behavior and cyberbullying," Comput. Educ., vol. 159, p. 104002, Dec. 2020, doi: 10.1016/j.compedu.2020.104002.

[7] F. N. Koranteng, I. Wiafe, and E. Kuada, "An Empirical Study of the Relationship Between Social Networking Sites and Students' Engagement in Higher Education," J. Educ. Comput. Res., vol. 57, no. 5, pp. 1131-1159, Sep. 2019, doi: 10.1177/0735633118787528.

[8] B. Wierenga, N. Althuizen, and B. Chen, "Managing the supply and demand of creativity," RSM Discov.-Manag. Knowl., vol. 31, no. 3, pp. 17-19, 2017.

[9] P. Josefsson, S. Hrastinski, D. Pargman, and T. C. Pargman, "The student, the private and the professional role: Students' social media use," Educ. Inf. Technol., vol. 21, no. 6, pp. 1583-1594, Nov. 2016, doi: 10.1007/s10639-015-9403-7.

[10] R. D. Axelson and A. Flick, "Defining Student Engagement," Change Mag. High. Learn., vol. 43, no. 1, pp. 38-43, Dec. 2010, doi: 10.1080/00091383.2011.533096.

[11] K.-L. Krause and H. Coates, "Students' engagement in first-year university," Assess. Eval.
High. Educ., vol. 33, no. 5, pp. 493-505, Oct. 2008, doi: 10.1080/02602930701698892.

[12] P. D. Umbach and M. R. Wawrzynski, "Faculty do Matter: The Role of College Faculty in Student Learning and Engagement," Res. High. Educ., vol. 46, no. 2, pp. 153-184, Mar. 2005, doi: 10.1007/s11162-004-1598-1.

[13] N. Zepke and L. Leach, "Improving student engagement: Ten proposals for action," Act. Learn. High. Educ., vol. 11, no. 3, pp. 167-177, Nov. 2010, doi: 10.1177/1469787410379680.

[14] V. H. K. Hung, M. Keppell, and M. S. Y. Jong, "Learners as producers: Using project based learning to enhance meaningful learning through digital video production," in Beyond the comfort zone: Proceedings of the 21st ASCILITE Conference, Perth, Australia, 2004, p. 9.

[15] C. A. Hafner and L. Miller, "Fostering Learner Autonomy in English for Science: A Collaborative Digital Video Project in a Technological Learning Environment," Lang. Learn., vol. 15, no. 3, pp. 68-86, 2011.

[16] L. Nikitina, "STUDENT VIDEO PROJECT AS A MEANS TO PRACTICE CONSTRUCTIVIST PEDAGOGY IN THE FOREIGN LANGUAGE CLASSROOM," J. Pendidik Dan Pendidik., vol. 24, pp. 165-176, 2009.

[17] J. Lim, H. H. Pellett, and T. Pellett, "Integrating Digital Video Technology in the Classroom," $J$. Phys. Educ. Recreat. Dance, vol. 80, no. 6, pp. 40-55, Aug. 2009, doi: 10.1080/07303084.2009.10598339.

[18] E. R. Hamilton, J. M. Rosenberg, and M. Akcaoglu, "The Substitution Augmentation Modification Redefinition (SAMR) Model: a Critical Review and Suggestions for its Use," TechTrends, vol. 60, no. 5, pp. 433-441, Sep. 2016, doi: 10.1007/s11528-016-0091-y.

[19] R. Geer, B. White, Y. Zeegers, W. Au, and A. Barnes, "Emerging pedagogies for the use of iPads in schools," Br. J. Educ. Technol., vol. 48, no. 2, pp. 490-498, 2017, doi: 10.1111/bjet.12381.

[20] D. Romrell, L. Kidder, and E. Wood, "The SAMR Model as a Framework for Evaluating mLearning," Online Learn. J., vol. 18, no. 2, Jun. 2014, Accessed: Oct. 16, 2020. [Online]. Available:

https://www.learntechlib.org/p/183753/.

[21] K. Walsh, "8 Examples of Transforming Lessons Through the SAMR Cycle | Emerging Education Technologies," Welcome to EmergingEdTech!, Apr. 20, 2015. https://www.emergingedtech.com/2015/04/examp les-of-transforming-lessons-through-samr/ (accessed Jul. 01, 2020). 
[22] M. Ovinis, S. Karuppanan, S. A. Sulaiman, P. S. Melor, M. Z. Paiz, and A. Urquia, "A Comparative Analysis of Attainment of Program Outcomes for Courses with and without the Use of Modern Tools," MATEC Web Conf., vol. 225, p. $\quad 06022, \quad 2018$, doi: 10.1051/matecconf/201822506022.

[23] The jamovi project, jamovi (Version 1.2). 2020.

[24] G. W. Corder and D. I. Foreman, Nonparametric statistics: a step-by-step approach, 2nd ed. Hoboken, New Jersey: John Wiley \& Sons, 2014. 